forms lacking the factor $\mathrm{E}$ which, when present, turns the eye dark and at the same time intensifies the coat colour. These corresponding forms may be set out as follows:

\section{Dark-eyed series}

Agouti . . . . . . . . EGBCh

Cinnamon agouti .... EGbCh

Black ... . . . . . EgBCh

Chocolate . . . . . . EgbCh

\section{Pink-eyed series}

eGBCh . pink-eyed agouti

eGbCh . pink-eyed, cinnamon agouti

egBCh . blue-lilac

egbCh . champagne

An additional form occurs in the lighter series owing to the fact that the heterozygous eeggBbChCh, is chocolate-lilac in colour, and quite distinct from the homozygous blue-lilac. Yellow mice may also be pink-eyed, and though in this variety also the colour is often more dilute when associated with the pink-eye, it may nevertheless be as dark as in the dark-eyed yellow.

The dilute colours in the pink-eyed series are entirely distinct from the dark-eyed dilute forms, blue agouti, blue, and silver-fawn. These last owe their paler colour to the lack of a distinct factor for intensification, $\mathbf{D}$. The factor D may however be borne by the pale pink-eyed forms, so that full black may result from the mating together of blue and champagne.

Other experiments were made with sables, yellow mice with a dark streak down the mid-dorsal region. The genetic behaviour of these mice is complicated, for while some of the results suggest that sable is recessive to yellow, others show that sables can throw some yellows. As in the case of yellows no homozygous sable mice were met with. R. C. Punnett.

\title{
Castle, W. E., and Phillips, J. C. On Germinal Transplantation in Vertebrates.
} Carnegie Institution, Publ. No. I44, Washington, I9II.

The authors made a number of experiments on ovarian transplantation in guinea-pigs, and also a few in rabbits. In most cases the grafted ovary failed to live, or else regeneration of the original ovary occurred. In two individuals however the operation was successful. The experiments were so arranged that the grafted ovary contained a dominant factor which was not present in the recessive parent from which the gland had been removed. Thus the ovaries of an albino guinea-pig were cut out and in their stead were grafted those from a female belonging to a pure black strain. The albino female with her "black" ovaries was crossed with an albino buck and produced six young, all of which were black. With her own ovaries she would have given nothing but albinos when mated with an albino buck. Hence her functional ovary must be regarded as that grafted in from the black female, and post mortem examination shewed this to be certainly the case.

As the result of their experiments the authors are on the whole opposed to the view that the hereditary properties of a grafted ovary are affected by the transplantation. Some criticism is given of the experiments of Magnus and of Guthrie whose conclusions the authors do not consider to be justified by their facts.

Some experiments were also made on the grafting of testicles in rats. In no case did the grafted organ live long in its host, and the experiments were soon discontinued.

The paper contains a brief review of the work hitherto done in grafting the sex glands, together with a bibliography of the subject.

R. C. Punnett. 